\title{
A decision support system based on support vector machine for diagnosis of periodontal disease
}

\author{
Maryam Farhadian ${ }^{1} \mathbb{0}$, Parisa Shokouhi ${ }^{2}$ and Parviz Torkzaban ${ }^{3 *}$
}

\begin{abstract}
Objective: Early diagnosis of many diseases is essential for their treatment. Furthermore, the existence of abundant and unknown variables makes more complicated decision making. For this reason, the diagnosis and classification of diseases using machine learning algorithms have attracted a lot of attention. Therefore, this study aimed to design a support vector machine (SVM) based decision-making support system to diagnosis various periodontal diseases. Data were collected from 300 patients referring to Periodontics department of Hamadan University of Medical Sciences, west of Iran. Among these patients, 160 were Gingivitis, 60 were localized periodontitis and 80 were generalized periodontitis. In the designed classification model, 11 variables such as age, sex, smoking, gingival index, plaque index and so on used as input and output variable show the individual's status as a periodontal disease.

Results: Using different kernel functions in the design of the SVM classification model showed that the radial kernel function with an overall correct classification accuracy of $88.7 \%$ and the overall hypervolume under the manifold (HUM) value was to 0.912 has the best performance. The results of the present study show that the designed classification model has an acceptable performance in predicting periodontitis.
\end{abstract}

Keywords: Periodontics, Support vector machine, Classification, Diagnosis, Machine learning, Decision support systems

\section{Introduction}

Development of diagnostic systems that help physicians to diagnose and make more precise decisions in the treatment of these diseases has become commonplace. These medical decision support systems (MDSS) help physicians and professionals make more accurate decisions and reduce possible errors [1-3]. Different machine learning algorithms are often used in decision-making systems. One of the broad and widely used areas of artificial intelligence is machine learning, which studies the ways and algorithms that enable computers and systems

\footnotetext{
*Correspondence: p.torkzaban@umsha.ac.ir

${ }^{3}$ Department of Periodontics, Dental School, Dental Research Center, Hamadan University of Medical Sciences, P.O. Box 4171-65175, Hamadan, Iran

Full list of author information is available at the end of the article
}

to learn and to perform actions $[4,5]$. Machine learning is related to topics such as data mining and statistics. Some machine learning applications include pattern recognition, data classification, and bioinformatics [4]. Powerful mathematical and statistical software has enabled the use of sophisticated approaches such as artificial neural networks and support vector machines (SVM) to predict and classify different outcomes [5, 6]. Using these tools can reduce the potential errors caused by fatigue or inexperience of clinical professionals in the diagnosis. Also, using these systems, the medical database can be analyzed in much less time and with further details.

As in all medical fields, successful dental treatment is possible only with the correct diagnosis of the disease. The diagnosis will be made by a bilateral examination of the clinical examination and radiography. In addition

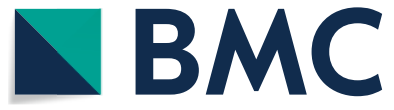

(c) The Author(s) 2020. This article is licensed under a Creative Commons Attribution 4.0 International License, which permits use, sharing, adaptation, distribution and reproduction in any medium or format, as long as you give appropriate credit to the original author(s) and the source, provide a link to the Creative Commons licence, and indicate if changes were made. The images or other third party material in this article are included in the article's Creative Commons licence, unless indicated otherwise in a credit line to the material. If material is not included in the article's Creative Commons licence and your intended use is not permitted by statutory regulation or exceeds the permitted use, you will need to obtain permission directly from the copyright holder. To view a copy of this licence, visit http://creativeco mmons.org/licenses/by/4.0/. The Creative Commons Public Domain Dedication waiver (http://creativecommons.org/publicdomain/ zero/1.0/) applies to the data made available in this article, unless otherwise stated in a credit line to the data. 
to these examinations, some other clinical examinations such as gingival index, plaque index, mobility index and clinical adhesion surface are used in the gum area [7-9]. However, these examinations may not be sufficient for a correct diagnosis.

In this regard, computer programs can help dentists to diagnose the disease as well as the correct path afterward. Along with the rapid development of computer technology, technology is still being developed in medicine, dentistry, and other medical fields $[10,11]$.

Periodontal disease is a common infectious disease in humans that is mainly caused by microbial plaque and various factors may affect or alter the manifestations of the disease. Although the potential impact of systemic disorders on periodontics has been proven, recent evidence suggests that periodontal infection may increase the likelihood of some systemic disorders or alter their natural course. Among the cases where the effects of periodontal infections have been proven, are cardiovascular disease (CHD) and complications of coronary heart disease such as angina pectoris and myocardial infarction $[12,13]$. Given the high prevalence of periodontal diseases in Third World societies, prevention, identification, and early treatment can help prevent systemic diseases caused by it. The purpose of this system is to accelerate and facilitate diagnostic processes and to help dentists make accurate decisions.

\section{Main text \\ Methods}

In this cross-sectional study, the records of 300 patients referred to the Periodontics department of Hamadan University of Medical Sciences, west of Iran, between September 2016 and June 2018 were studied. Based on consultation with two experienced professionals of periodontology as well as a review of clinical studies, the desired variables were selected [14, 15, 21, 23]. The corresponding values of the selected variables were extracted and recorded for each patient with full confidentiality principles. This study was approved by the Research Ethics Committee of Hamadan University of Medical Sciences with IR.UMSHA.REC.1398.154.

\section{Support vector machine}

SVM is one of the supervised learning methods used for classification and regression. SVM is based on the theory of statistical learning. SVM is an algorithm that finds a particular type of linear model that maximizes the margin of hyper-planes. Maximizing the hyper-planes margin will maximize the separation between classes. The closest training points to the maximum cloud margin are the support vectors. Only these vectors (points) are used to specify the boundary between classes (Fig. 1).

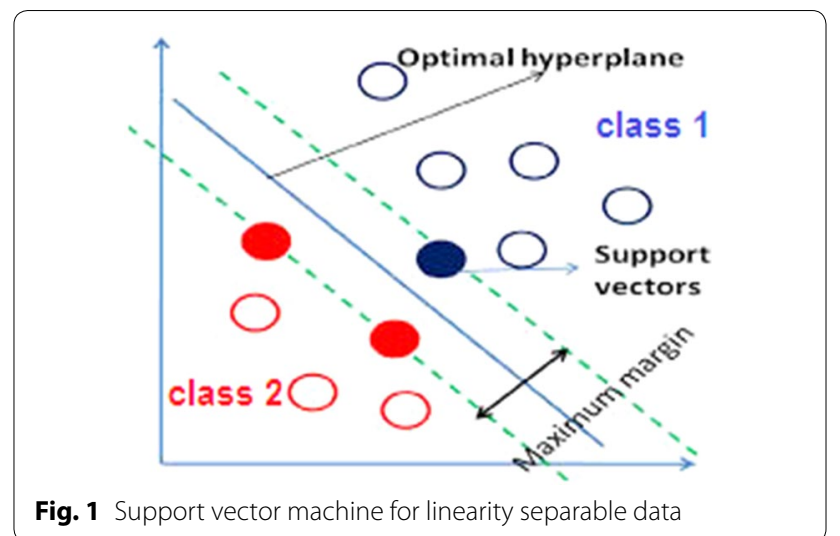

Assuming that the categories are linearly separable, it obtains the hyper planes with the maximum margin to separate the categories. The problem of finding the optimal line for the data is done by QP methods, which are well-known methods for solving constrained problems [16].

In problems where the data are not linearly separable, using a kernel function the data is mapped to a larger dimensional space so that it can be linearly separated in this new space. In this situation, various kernel functions, such as linear, radial, polynomials and sigmoid can be used [17].

\section{Model performance evaluation}

Cross-validation is a technique for assessing how the results of a predicting model such as SVM will generalize to an independent data set. The goal of cross-validation is to test the model's ability to predict new data that was not used in constructing it.

One round of cross-validation involves splitting the entire data randomly into $\mathrm{k}$ subsets (folds), then the predictive model construct based on one subset (called the training set), and predictive performance evaluate based on the other subset (called the validation set or testing set). This process repeats until every K-fold serves as the test set. Finally, recorded accuracy measures combined (averages) to derive a more accurate estimate of model prediction performance [4].

Also, we try hypervolume under the ROC manifold (HUM) as an alternative error measure for evaluating the SVM model. Unlike the overall correct classification accuracy measure, HUM does not depend on the class prevalence and thus reflects the intrinsic accuracy of the classifier [18].

It should also be noted that in the current study the professional's diagnosis is considered as the gold standard for evaluating the predictive performance of the model. 


\section{Building a SVM classification model}

In SVM classification model, the variables including age (continues), sex (male, female), smoking (yes, no), attachment loss (continues), plaque index (percent), probing packet depth (continues), gingival index (grade I, grade II, grade III, grade IV), alveolar bone loss (score: 0 for $\mathrm{ABL} \leq 20 \%, 1$ for $20 \leq \mathrm{ABL} \leq 50 \%, 2$ for $\mathrm{ABL} \geq 50 \%$ based on radiography), papilla bleeding index $(0,1,2,3)$, mobility (no, yes), and simplified oral hygiene index $(0,1,2,3)$ used as input and the individual's status of periodontal disease as output variable consists of three class (gingivitis, localized periodontitis, generalized periodontitis). Also, different kernel functions such as linear kernel, polynomial, sigmoid, and radial evaluated. To evaluate the performance of the SVM model, the accuracy criterion and the configuration of the confusion matrix was used.

All analyses were performed by using "caret", "HUM" and "mcca" a freely available package from the Comprehensive R (R3.6.3) Archive Network (CRAN).

\section{Results}

Table 1 compares the mean of continuous variables related to attachment loss, plaque index, probing pocket depth and age in three groups. The results showed that the mean difference of attachment loss, plaque index, probing pocket depth variables in the three groups was significant, but the mean age was not significant in the three groups. Table 1 also shows the frequency distribution of variables such as gender, smoking, gingival index, papilla bleeding index, alveolar bone loss and oral health in groups. The results show that the groups are not sexually different. There was a significant difference between the three groups in all variables. In Table 2, a comparison of the performance of different SVM models based on different kernel functions in terms of the accuracy index and HUM values based on tenfold cross validation is presented. The results show that the SVM classification model based on radial kernel function has the best performance with an overall correct classification accuracy of $88.7 \%$ using tenfold cross-validation method. Also, category-specific correct classification for gingivitis was $96.0 \%$, for localized periodontitis was $64.0 \%$, and for generalized periodontitis was $92.2 \%$. Further evaluation of the SVM model using HUM criteria showed the overall HUM value was equal to 0.912 .

\section{Discussion}

In this study, the SVM classification method was used to classify patients with periodontitis. The results of the present study show that the designed classification model has an acceptable performance in predicting periodontitis. Using a precise model to predict periodontal disease can be helpful to dentists with little experience. In fact, the use of such systems can lead to a decrease in fear (due to lack of knowledge, skills, being alone) and increased self-esteem, especially in young physicians. The development and evolution of these systems can provide the satisfaction of the stakeholders of health care systems and it is also possible that by design and using decisionmaking systems in physician assistant's portable devices or medical computers in medical offices providing realtime medical tools to clinical practitioners to make more reliable diagnoses $[19,20]$.

Several studies confirmed that the prevalence and severity of periodontal disease increase with age [21]. A similar finding has been observed in the present study, although there was no statistically significant difference in mean age between different classes of the disease, the average age of patients increased with increasing severity of the disease.

There is accumulating evidence for a higher level of periodontal disease among smokers [21]. In the present study, the percentage of smokers increased with increasing severity of the disease.

In the following, the classification model presented in this study will be compared with some studies related to the prediction of periodontitis.

Ozden et al., conducted a study on the 150 periodontal patients. Three classification models including support vector machine, decision tree and neural network were used in this study. Among them, support vector machine and decision tree have higher accuracy for classification of periodontal disease, with $98 \%$ accuracy and the worst performance is the ANN with an accuracy of 46\% [22].

Youssif et al., conducted a study on 30 patients based on clinical data including plaque index, pocket depth, and clinical attachment level as well as data from Hematoxylin and Eosin lam prepared from individuals which were divided into three diagnostic groups: gingival enlargement, chronic periodontitis and chronic gingivitis. The statistical model used is Feed Forward, Back propagation ANN with a precision rating of $100 \%$ [8].

Arbabi et al., conducted a study in Iran. They divided 190 patients into two groups ( $\mathrm{n}=160$ for train) and $(\mathrm{n}=30$ for test $)$ and studied them by examining age, sex, plaque index, probing pocket depth, and clinical attachment loss index as an input variables. Two LevenbergMarquardet (LM) and Scaled Conjugate Gradient (SCG) algorithms have been used in this work, results showed that a better performance for the LM than SCG [23].

Papantonopoulos et al., used Artificial Neural Network Model (ANN) along with patients information's to classifying patients in two categories of chronic periodontitis and aggressive periodontitis. The accuracy of ANN for classification of data was 90-98\% [24]. 
Table 1 Comparison of different variables between three classes of diseases (Hamadan in the west of Iran- September 2016 to June 2018)

\begin{tabular}{|c|c|c|c|c|c|c|c|}
\hline \multicolumn{8}{|l|}{ Class } \\
\hline \multirow[t]{2}{*}{ Variable } & & \multirow{2}{*}{$\begin{array}{l}\text { Gingivitis } \\
\text { Mean } \pm \text { SD }\end{array}$} & \multicolumn{2}{|c|}{ Localized periodontitis } & \multirow{2}{*}{\multicolumn{2}{|c|}{$\begin{array}{l}\text { Generalized periodontitis } \\
\text { Mean } \pm \text { SD }\end{array}$}} & P-value* \\
\hline & & & \multicolumn{2}{|c|}{ Mean \pm SD } & & & \\
\hline \multicolumn{2}{|l|}{ Age } & $32.91 \pm 10.77$ & \multicolumn{2}{|c|}{$33.88 \pm 10.52$} & \multicolumn{2}{|r|}{$34.23 \pm 12.38$} & 0.656 \\
\hline \multicolumn{2}{|c|}{ Attachment loss } & $1.63 \pm 0.47$ & \multicolumn{2}{|c|}{$2.24 \pm 0.61$} & \multicolumn{2}{|r|}{$3.39 \pm 0.81$} & $<0.001$ \\
\hline \multicolumn{2}{|c|}{ Plaque Index (\%) } & $43.46 \pm 17.82$ & \multicolumn{2}{|c|}{$62.13 \pm 17.80$} & \multicolumn{2}{|r|}{$74.55 \pm 15.09$} & $<0.001$ \\
\hline \multicolumn{2}{|c|}{ Probing packet depth } & $1.48 \pm 0.32$ & \multicolumn{2}{|c|}{$2.01 \pm 0.54$} & \multicolumn{2}{|r|}{$3.25 \pm 0.78$} & $<0.001$ \\
\hline & $n$ & $\%$ & $n$ & $\%$ & $n$ & $\%$ & P-value** \\
\hline \multicolumn{8}{|l|}{ Sex } \\
\hline Female & 65 & 40.6 & 19 & 31.7 & 29 & 36.3 & 0.453 \\
\hline Male & 95 & 59.4 & 41 & 68.3 & 51 & 63.8 & \\
\hline \multicolumn{8}{|l|}{ Smoking } \\
\hline No & 148 & 92.5 & 54 & 90 & 65 & 81.2 & 0.031 \\
\hline Yes & 12 & 7.5 & 6 & 10 & 15 & 18.8 & \\
\hline \multicolumn{8}{|c|}{ Gingival Index } \\
\hline Grade I & 48 & 30 & 6 & 10 & 5 & 15 & $<0.001$ \\
\hline Grade II & 78 & 48.8 & 24 & 40 & 27 & 33.8 & \\
\hline Grade III & 31 & 19.4 & 26 & 43.3 & 39 & 43.8 & \\
\hline Grade IV & 3 & 1.9 & 4 & 6.7 & 9 & 7.6 & \\
\hline \multicolumn{8}{|c|}{ Alveolar Bone Loss } \\
\hline 0 & 153 & 95.6 & 7 & 11.7 & 2 & 2.5 & $<0.001$ \\
\hline 1 & 4 & 2.5 & 18 & 30.0 & 32 & 40.0 & \\
\hline 2 & 3 & 1.9 & 35 & 58.3 & 46 & 57.5 & \\
\hline \multicolumn{8}{|c|}{ Papilla Bleeding Index } \\
\hline 0 & 41 & 25.6 & 8 & 13.3 & 9 & 11.3 & $<0.001$ \\
\hline 1 & 78 & 48.8 & 22 & 36.7 & 13 & 16.3 & \\
\hline 2 & 37 & 23.1 & 23 & 38.3 & 41 & 33.7 & \\
\hline 3 & 4 & 2.5 & 7 & 11.7 & 17 & 9.3 & \\
\hline \multicolumn{8}{|l|}{ Mobility } \\
\hline No & 140 & 87.5 & 35 & 58.3 & 46 & 57.5 & $<0.001$ \\
\hline Yes & 20 & 12.5 & 25 & 41.7 & 34 & 42.5 & \\
\hline Simplified & ndex & & & & & & \\
\hline 0 & 5 & 3.1 & 9 & 15 & 10 & 12.5 & $<0.001$ \\
\hline 1 & 16 & 10.0 & 16 & 26.7 & 11 & 13.8 & \\
\hline 2 & 79 & 49.4 & 24 & 40.0 & 40 & 50.0 & \\
\hline 3 & 60 & 37.5 & 11 & 18.3 & 19 & 23.8 & \\
\hline
\end{tabular}

*ANOVA

${ }^{*}$ Chi Square Test

Table 2 Comparison of the performance of different kernel functions (tenfold cross validation)

\begin{tabular}{lll}
\hline Kernel & Accuracy & HUM value \\
\hline Linear & 0.817 & 0.831 \\
Polynomial & 0.811 & 0.839 \\
Radial & 0.887 & 0.912 \\
Sigmoid & 0.875 & 0.892 \\
\hline
\end{tabular}

HUM hypervolume under the manifold
In fact, there is no biological or computational reason why a particular classification method is better for predicting the result under different conditions. In general, it is not possible to find a method that is always the best for classifying different data sets. Therefore, more research is needed to find the best classifier for each data set.

In our opinion, more accurate results can be obtained when more patients with various types of persistent 
systemic and periodontal problems are added to the system. It is likely that the classification performances could be improved with the use of some other classifiers, future investigations can focus on different classification model such as fuzzy expert systems. Future studies can be performed to identify the most important predictive variables such as inflammatory markers, systemic factors, stress, and educational levels in the classification of periodontitis.

\section{Conclusions}

The decision-making support system based on support vector machine was highly accurate for the diagnosis of periodontal disease. Designing accurate decision-making support systems facilitate and accelerate diagnostic processes. The system designed in this study will help less experienced dentists and young residents in making decisions for the diagnosis of periodontal disease.

\section{Limitations}

Although from a practical point of view, the ability to repeat valid results in the real data is guaranteed by cross-validation method, however, any predictive model that uses professional's diagnosis as a gold standard is prone to inherent uncertainty due to incorrect classification by whom, and this will remain not only in the present study but in all studies with this approach. However, the hope is that using the diagnosis of an experienced professional will be overcome this limitation.

\section{Abbreviations \\ SVM: Support Vector Machine; MDSS: Medical Decision Support Systems; AL: Attachment Loss; PI: Plaque Index; PPD: Probing Packet Depth; Gl: Gingival Index; ABL: Alveolar Bone Loss; PBI: Papilla Bleeding Index; MB: Mobility.}

\section{Acknowledgements}

This study is the result of research project No. 9802311768 of Hamadan University of Medical Sciences. The authors would like to appreciate the financial support of the Hamadan University of Medical Sciences.

\section{Authors' contributions \\ MF prepare proposals, set and analysis the results of the studies and their interpretation, Prepare and interpret data, prepare a final report, prepare results, writing the article. PT supervised the design and execution of the study and revising the article. PSH collected the data and contributed to prep- aration of the proposal. All authors read and approved the final manuscript.}

\section{Funding}

This study was supported by Vice-Chancellor of Research and Technology of Hamadan University of Medical Sciences, Contractor No. 9802311768 . Funder had no role in the design of the study and collection, analysis, and interpretation of data and in writing the manuscript.

\section{Availability of data and materials}

The datasets during and/or analyzed during the current study available from the corresponding author on reasonable request.

\section{Ethics approval and consent to participate}

This study was approved by the Ethics Committee of Hamadan University of Medical Sciences with IR.UMSHA.REC.1398.154. All the participants were informed on the purpose of the study and on confidentiality and they were free to participate, refuse or withdraw at any time of the procedure. Written informed consent was obtained from all individual participants included in the study.

\section{Consent to publish}

Not applicable.

\section{Competing interests}

The authors declare that they have no competing interests.

\section{Author details}

${ }^{1}$ Department of Biostatistics, School of Public Health and Research Center for Health Sciences, Hamadan University of Medical Sciences, Hamadan, Iran. 2 Dental School, Hamadan University of Medical Sciences, Hamadan, Iran.

${ }^{3}$ Department of Periodontics, Dental School, Dental Research Center, Hamadan University of Medical Sciences, P.O. Box 4171-65175, Hamadan, Iran.

Received: 7 March 2020 Accepted: 8 July 2020

Published online: 13 July 2020

\section{References}

1. Milovic B, Milovic M. Prediction and decision making in health care using data mining. IJPHS. 2012;1(2):69-78.

2. Vikram K, Karjodkar FR. Decision support systems in dental decision making: an introduction. J Evid Based Dent Pract. 2009;9:73-6.

3. Lisboa PJG, Taktak A. The use of artificial neural networks in decision support in cancer: a systematic review. Neural Networks. 2006;19:408-15.

4. Hastie T, Tibshirani R, Friedman J. The elements of statistical learning: data mining, inference, and prediction. 2nd ed. New York: Springer Series in Statistics; 2009

5. Lisboa PJG. A review of evidence of health benefit from artificial neural networks in medical intervention. Neural Netwk. 2002;15(1):11-39.

6. Farhadian M, Salemi F, Saati S, Nafisi N. Dental age estimation using the pulp-to-tooth ratio in canines by neural networks. Imaging Sci Dent. 2019;49(1):19-26

7. Van Der Velden U. Purpose and problems of periodontal disease classification. Periodontol 2000. 2005;39:13-21.

8. Youssif AA, Gawish AS, Moussa ME. Automated periodontal diseases classification system. Int J Adv Comput Sci Appl. 2012;3(1):40-8.

9. Armitage GC. Periodontal diagnoses and classification of periodontal diseases. Periodontol 2000. 2004;34:9-21.

10. Devito KL, de Souza Barbosa F, Felippe Filho WN. An artificial multilayer perceptron neural network for diagnosis of proximal dental caries. Oral Surg Oral Med Oral Pathol Oral Radiol Endod. 2008;106(6):879-84.

11. Tonetti MS, Claffey N. Advances in the progression of periodontitis and proposal of definitions of a periodontitis case and disease progression for use in risk factor research. J Clin Periodontol. 2005;32(s6):210-3.

12. Eke PI, Dye BA, Wei L, Thornton-Evans GO, Genco RJ. Prevalence of periodontitis in adults in the United States: 2009 and 2010. J Dent Res. 2012;91:914-20.

13. Laine ML, Crielaard W, Loos BG. Genetic susceptibility to periodontitis. Periodontol 2000. 2012;58:37-68.

14. Tanner ACR, Dyke TV, Sonis ST, Murray LA. Clinical and other risk indicators for early periodontitis in adults. J Periodontol. 2005;76(4):573-81.

15. Reddy MS, Geurs NC, Jeffcoat RL, Proskin H, Jeffcoat MK. Periodontal disease progression. J Periodontol. 2000;71(10):1583-90.

16. Vapnik V. The nature of statistical learning theory. New York: Springer; 1995.

17. Vapnik V. Statistical learning theory. New York: Wiley; 1998.

18. Li J, Gao M, D'Agostino R. Evaluating classification accuracy for modern learning approaches. Stat Med. 2019;38(13):2477-503. https://doi. org/10.1002/sim.8103.

19. Khoramian TS, Zeynali B. Investigation of a decision making system for dental caries treatment in children. J Develop Strat Med Educ. 2014;1 (1):37-44 (in Persian).

20. Mago V, Prasad B, Bhatia A, Mago A. A decision making system for the treatment of dental caries. Soft Comput App Bus. 2008;4:231-42. 
21. AlJehani YA. Risk factors of periodontal disease: review of the literature. Int J Dent. 2014;2014:182513.

22. Özden FO, Özgönenel O, Özden B, Aydoğdu A. Diagnosis of periodontal diseases using different classification algorithms: a preliminary study. Niger J Clin Pract. 2015;18:3.

23. Arbabi S, Firouzi Jahantigh F, Ansari Moghadam S. Presenting a model for periodontal disease diagnosis using two artificial neural network algorithms. Health Scope. 2018;7(3):e65330.
24. Papantonopoulos G, Takahashi K, Bountis T, Loos BG. Artificial neural networks for the diagnosis of aggressive periodontitis trained by immunologic parameters. PLoS ONE. 2014;9(3):89757.

\section{Publisher's Note}

Springer Nature remains neutral with regard to jurisdictional claims in published maps and institutional affiliations.
Ready to submit your research? Choose BMC and benefit from:

- fast, convenient online submission

- thorough peer review by experienced researchers in your field

- rapid publication on acceptance

- support for research data, including large and complex data types

- gold Open Access which fosters wider collaboration and increased citations

- maximum visibility for your research: over $100 \mathrm{M}$ website views per year

At BMC, research is always in progress.

Learn more biomedcentral.com/submissions 